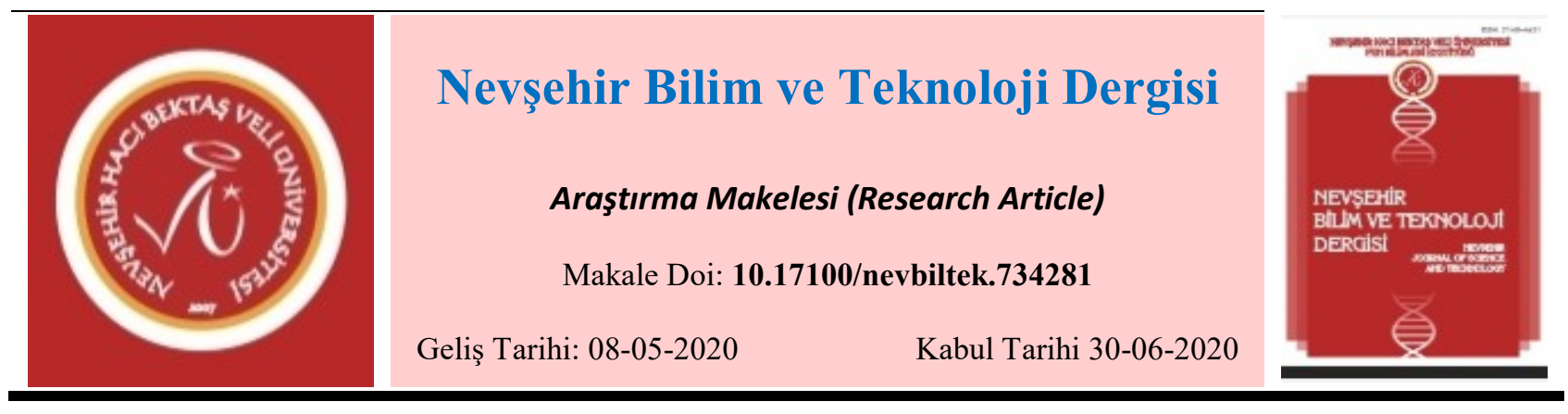

\title{
1,2344 Sıcak İş Takım Çeliğinin Kutu Sementasyon Yöntemi ile Vc Kaplanabilirliğinin İncelenmesi \\ Yusuf KARACA
}

Nevşehir Hacı Bektaş Veli Üniversitesi, Kapadokya Teknopark, BC Teknoloji Danışmanlık İmalat, Nevşehir ORCID ID: 0000-0002-4885-6612

$\ddot{\mathbf{O z}}$

Makine ve otomotiv parçalarında genel olarak kullanılan takım çeliklerin ömürleri aşınmalar ile sınırlıdır. Bundan dolayı aşınmaların önlenebilmesi, ekonomik açıdan ciddi anlamda kazanç sağlayacaktır. Son zamanlarda bu problemleri azaltmak ya da ortadan kaldırmak için yeni nesil takım çelikleri ve takım çeliklerinin iyileştirilmesi üzerine çalışmalar artmışır. Takım çeliklerinin iyileştirilmesi için yapılan çalışmalardan bir tanesi de kaplama yöntemleridir. Yüzeylerdeki aşınma ve korozyona karşı dayanımları artırmak amacı ile kaplamalar son zamanlarda oldukça öne çıkmaktadır. Bu çalışmada 1,2344 sıcak iş takım çelikleri kutu sementasyon yöntemi (TRD) kullanılarak farklı sıcaklıklarda 2 saat süre ile Vanadyum Karbür (VC) kaplama gerçekleştirilmiştir. VC kaplama ile aşınmaya ve korozyona karşı dayanımı artırmak ve ekonomiye katkı sağlamak amaçlanmıştır. VC ile kaplanmış numunelerin mikroyapı incelemeleri ve sertlik testleri yapılmıştır. Elde edilen mikroyapı ve sertlik değerlerinin literatür ile karşılaştırılarak tartı̧̧ılmıştır.

Anahtar Kelimeler: Takım Çeliği, VC Kaplama, Mikroyapı, Sertlik

\section{Investigation of Ve Coatability Of 1.2344 Hot Work Tool Steel With Box Cementation Method}

Abstract

The life of tool steels commonly used in machinery and automotive parts is limited to wear. Therefore, preventing abrasions will provide a significant economic gain. Recently, studies on the improvement of new generation tool steels and tool steels have been increased in order to reduce or eliminate these problems. Coating methods are one of the studies carried out to improve tool steels. Coatings have become very prominent recently in order to increase the resistance against abrasion and corrosion on the surfaces. In this study, Vanadium Carbide (VC) coating was carried out for 2 hours at different temperatures using 1.2344 hot work tool steels box cementation method (TRD). With VC coating, it is aimed to increase the resistance against abrasion and corrosion and contribute to the economy. Microstructures and hardness tests of VC coated samples were performed. The microstructure and hardness values obtained were discussed by comparing them with the literature.

Keywords: Tool Steel, VC Coating, Microstructure, Hardness

Bu çalışma, ' 'The International Conference on Material Science and Technology (IMSTEC)’’ sempozyumunda sözlü sunum gerçekleştirilmiştir. 


\section{Giriş}

Çelikler geliştirilebilir mekanik özelliklerinden dolayı günümüzde otomotiv, inşaat, tıp ve havacılık sektöründe yaygın olarak kullanılmaktadır. Kimyasal kompozisyonlarının değiştirilmesi yada ısıl işlem uygulanmalarından dolayı yapısal olarak davranışlarının geliştirilmesi birçok uygulamaların kullanılmasının ana sebebidir. Bu uygulamalarda kullanılan çeliklerden biri de sıcak iş takım çelikleridir. Sıcak iş takım çelikleri günümüz endüstriyel uygulamalarında çok büyük öneme sahiptir. Sıcak iş takım çelikleri kullanım alanları demir esaslı ve demir dışı metallerin dövülerek şekillendirilmesi, hafif metal ekstrüzyonu ve yüksek basınçlı döküm uygulamalarıdır [1]. Sıcak iş takım çelikleri içerdikleri prensip alaşım elamanına göre üç grup altında toplanmaktadır. Bunlar, Cr esaslı sıcak iş takım çelikleri, Molibden esaslı sıcak iş takım çelikleri ve Tungsten esaslı takım çelikleridir [2]. Bu çalışmada ise Cr esaslı 1,2344 sıcak iş takım çeliği kullanılmaktadır. Nurşen S. ve arkadaşları tarafından X55NiCrMoV7 $(1,2714)$ sıcak iş takım çeliğine Coesaslı sert kaplama yapılarak aşınma dayanımları incelemiştir. Co içerikli yapılan malzemenin sertliği max $450 \mathrm{HV}$ görülmektedir. [3]

$\mathrm{Bu}$ çalışmada, $\mathrm{Cr}$ esaslı 1,2344 sıcak iş takım çeliklerine TRD yöntemi ile $900{ }^{\circ} \mathrm{C}, 1000{ }^{\circ} \mathrm{C}$ ve $11100{ }^{\circ} \mathrm{C}$ sıcaklıklarda yaklaşık 2 saat bekletilerek VC kaplama yapılarak mikroyapı ve sertlik değerleri incelenmiştir. Sıcak iş takım çeliklerin mikrosertlik değerleri yükseltilerek sektörde ve akademik çalışmaların literatürüne katkı sağlayacaktır.

2. Materyal ve Metot

Çalışmada kullanılan 1,2344 sıcak iş takım çelikleri Sağlam Metal A.Ş./İzmir'den temin edilmiştir. Temin edilen Cr esaslı 1,2344 sıcak iş takım çeliklerinin kompozisyonu Tablo 1.'de verilmektedir.

Tablo 1. 1,2344 sıcak iş takım çeliğinin kimyasal kompozisyonu (Ă̆ırlık \%)

\begin{tabular}{ccccc}
\hline Malzeme & $\mathrm{C}(\%)$ & $\mathrm{Cr}(\%)$ & Mo $(\%)$ & V (\%) \\
DIN 1,2344 & 0,40 & 5,30 & 1,40 & 1 \\
\hline
\end{tabular}

1,2344 sıcak iş takım çelik numuneler $15 \times 15 \times 10 \mathrm{~mm}$ boyutlarında kare şeklinde Metkon Metacut 250 markalı hassas kesme cihazında kesilmiştir. Hassas kesilen numuneler Şekil 1'deki çelik sızdırmaz potalar kullanılarak max 1200 ${ }^{0} \mathrm{C}^{\prime}$ lik firında kaplama işlemi gerçekleştirilmiştir.

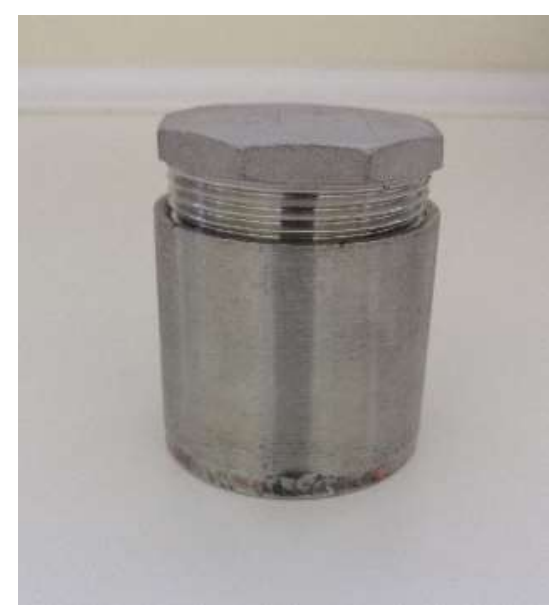

Şekil 1. Sızdırmaz pota

Kesim işlemi gerçekleştirilen üç adet numunenin tüm yüzeyleri 120, 400, 800 ve 1200 mesh'lik zımpara ile Metkon Forcipol 2V markalı cihazda zımparalama ve parlatma işlemleri yapılmıştır. Pota içerisine 65 mikron altı Ferro 
Nevşehir Bilim ve Teknoloji Dergisi (2019), 9 (IMSTEC Özel Sayı),106-110

Vanadyum, $\mathrm{Al}_{2} \mathrm{O}_{3}$ ve $\mathrm{NH}_{4} \mathrm{Cl}$ ilave edilmiştir. Daha sonra numuneler yerleştirilmiş ve bir miktarda silisyum karbür ve dökme demir talaşı eklenerek numunelerin üzeri kapatılmıştır. Böylece numunelere oksijenin difüze olmasının önüne geçmek amaçlanmıştır. Yüzeyler temizlenmiş numuneler potaya yerleştirilmiş ve potanın ağzı sıkıca kapatılmıştır. Hazırlanan pota $900{ }^{\circ} \mathrm{C}, 1000{ }^{\circ} \mathrm{C}$ ve $1100{ }^{\circ} \mathrm{C}^{\prime}$ lerde 2 saat süre tutularak kaplama işlemi gerçekleştirilmiştir. Fırından çıkarılan pota hava ortamında soğutulmuş ve kapağı açılarak numuneler üzerindeki kalıntıları gidermek amacı ile 800 mesh'lik zımpara ile zımparalanma işlemi gerçekleştirilmiştir.

Kutu sementasyon tekniği ile VC kaplama yapılan numuneler öncelikli olarak Metkon Ecopress 50 marka sıcak bakalit kalıplama cihazı kullanılarak kalıplama işlemi yapılmışır. Kalıplanan numuneler 120 mesh'lik zımpara ile ana malzemeye ulaşıncaya kadar zımparalanmıştır. Ana malzemeye ulaşıldıktan sonra 400, 800 ve 1200 mesh'lik zımparalar ile zımparalanmış ve parlaklık vermek için 0,25 mikronluk elmas solüsyon ile çuhada parlatılmıştır. Daha sonra \%3' lük Nital çözeltisi ile dağlanma işlemi gerçekleştirilerek optik mikroyapılar Nikon MA 100 markalı mikroskop ile incelenmiştir.

Mikroyapıları incelenen numuneler Future Tech FM-700 marka mikro sertlik cihazı kullanılarak sertlik analizi gerçekleştirilmiştir. Sertlik testi, kaplama tabakasından ve kaplama sonrası ana malzemeden ölçülmüştür. Mikro sertlik ölçümü 24 gf yük altında, 10 sn. süre ile yapılmıştır.

\section{Bulgular ve Tartışma}

Bu çalışmada, 1,2344 sıcak iş takım çeliğinin TRD yöntemi kullanılarak, 900, 1000 ve $1100{ }^{\circ} \mathrm{C}^{\prime}$ lik sıcaklıklarda 2 saat sürelerde tutularak VC ile kaplanmıştır. Kaplama işlemi sonrası, kaplama tabakası optik mikroskop ve sertlik testlerine tabi tutulmuştur. Böylece optimum kaplama kalınlığı ve özelliğine sahip parametreler ile sertlik değeri belirlenmiştir.

\section{a. Kaplama Tabakası Optik Mikroyapısı}

1,2344 sıcak iş takım çeliği 900,1000 ve $1100^{\circ} \mathrm{C}^{\prime}$ lik sıcaklıklar ve 2 saat sürelerde VC kaplanmış ve kaplama tabakası kesitinin optik analiz sonuçları sıcaklık artışa bağlı olarak değerlendirilmiştir. Bu amaçla, Şekil 2'de $900{ }^{\circ} \mathrm{C}$ ' lik $1000{ }^{\circ} \mathrm{C}$ ve $1100{ }^{\circ} \mathrm{C}$ sıcaklıkta 2 saat süre bekletilen numunelerden alınan optik fotoğraflar verilmiştir. 

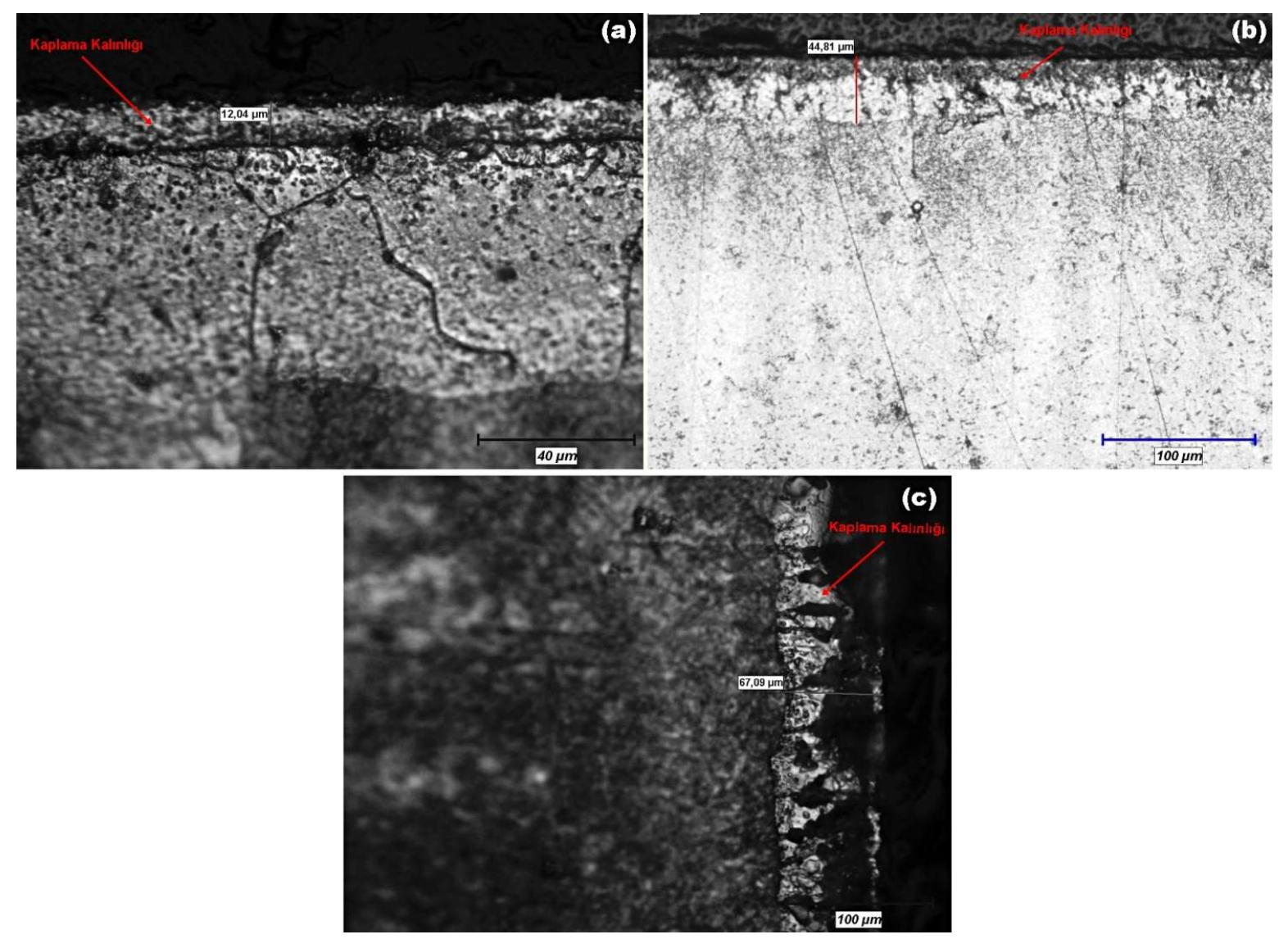

Şekil 2. (a) $900{ }^{\circ} \mathrm{C}^{\prime}$ de ki kaplama görüntüsü, (b) $1000{ }^{\circ} \mathrm{C}^{\prime}$ de ki kaplama görüntüsü (c) $1100{ }^{\circ} \mathrm{C}^{\prime}$ de ki kaplama kalınlığı görüntüsü

Şekil 2. a), b) ve c)'de verilen mikroyapı görüntüleri incelendiğinde sıcaklığın artması ile birlikte tane boyutlarında belirgin bir değişiklik gözlenmemiştir. Yapılan VC kaplamaların tabakalarının homojen olarak kaplandığı Şekil 2. de görülmektedir. VC kaplama tabakası sıcaklığın yükselmesi ile kaplama kalınlı̆̆ının arttığı görülmektedir. 900 ${ }^{0} \mathrm{C}$ 'de VC kaplama kalınlığı $12.04 \mu m$ iken, $1100{ }^{\circ} \mathrm{C}^{\prime}$ de VC kaplama kalınlığı $67.09 \mu m$ değerine ulaşmıştır. Bu durum sertlik değerlerindeki artış ile paralel olması olumlu görülmüştür. Chicco ve arkadaşları, sıcak iş takım çeliklerini VC ve VN ile kaplama işlemi yapmışlardır. Kaplama işlemini $570^{\circ} \mathrm{C}$ ve 36 saat süre beklemişlerdir. VC kaplamanın $5 \mu$ değerinde olduğu VN kaplamanın ise yaklaşık olarak $10 \mu$ olduğu görülmüştür [4].

\section{b. Sertlik Analizi}

1,2344 sıcak iş takım çeliği $900{ }^{\circ} \mathrm{C}, 1000{ }^{\circ} \mathrm{C}$ ve $1100{ }^{\circ} \mathrm{C}^{\prime}$ lik sıcaklıklar ve 2 saat sürelerde VC kaplanmış ve kaplama tabakası kesitinin sertlik sonuçları sıcaklık artışa bağlı olarak Tablo 2.'de verilmiştir. Sertlik testi; kaplama sonrası ana malzeme ve kaplama olmak üzere iki bölgeden incelenmiştir.

Tablo 2. Kaplama sonrası ana malzeme ve kaplama sertlik değerleri

\begin{tabular}{ccc}
\hline Sıcaklık & $\begin{array}{c}\text { Kaplama Sonrası Ana } \\
\text { Malzeme Sertliği (HV) }\end{array}$ & Kaplama sertliği (HV) \\
$900^{\circ} \mathrm{C}$ & 584,775 & 1050,27 \\
$1000^{\circ} \mathrm{C}$ & 694,191 & 1180,60 \\
$1100^{\circ} \mathrm{C}$ & 809,083 & 1401,56 \\
\hline
\end{tabular}

Kaplama sonrası ana malzeme sertlikleri, sıcaklık değeri artıkça sertlik değerlerinde artış gözlenmiştir. Fakat kaplama sertliği çok yükselmiş ve belirgin bir şekilde 1050 HV değerlerinden sıcaklık artıkça 1401 HV değerine çıkmıştır. Bu değerler 1,2344 sıcak iş takım çeliğinin aşınma ömrünü ve korozyon direncini artıracaktır. Batista ve 
arkadaşlarının, AISI H13 sıcak iş takım çeliklerinin aşınma testlerini incelemek üzere yapmış oldukları TiN kaplamada ana malzeme yüzeyinde ki sertlik değeri 719 HV iken kaplama kalınlık sertlik değeri 2509 HV görülmektedir [5]. L.H. Chiu ve ark. Tarafından AISI H13 sıcak iş takım çeliklerine krom ve krom nitrür kaplama yapılarak aşınma değişimimleri tespiti yapmışlardır. Yapılan kaplamada ana malzeme kaplama sertliği 400 HV iken, kaplama kalınlık sertliği 900 HV civarında olduğu görülmektedir [6].

\section{Sonuçlar}

1,2344 sıcak iş takım çeliği farklı sıcaklıklarda 2 saat süre ile TRD yöntemi ile VC kaplanmıştır. Kaplama işlemi sonrası numuneler optik mikroskop ile incelenmiş ve mikro sertlik test analizleri yapılmıştır.

- Sıcaklığın artması ile birlikte tane boyutlarında belirgin bir değişiklik gözlenmemiştir.

- Elde edilen VC kaplama tabakalarının homojen olarak kaplandığı görülmüştür.

- VC kaplama tabakası, sıcaklığın artmasıyla kaplama kalınlığının da arttığı görülmüştür.

- Kaplama sonrası ana malzeme sertlikleri, sıcaklık değeri artıkça sertlik değerlerinde artış gözlenmiştir.

\section{Kaynaklar}

[1]. Asan, N.Ö., ' 'Sıcak İş Takım Çeliklerinde Hasar Oluşumu ve Önlemleri', Y.T.Ü., Fen Bilimleri Enstitüsü, S.2$6,2008$.

[2]. Önder, E., ' 'Termoreaktif difüzyon (TRD) yöntemiyle krom karbür ve vanadyum karbür kaplanan AISI D3 seri soğuk iş takım çeliğinin mikroyapı ve aşınma özelliklerinin incelenmesi’, Bartın Üniversitesi Fen Bilimleri Enstitüsü, S.1-43, 2012.

[3]. Saklakoğlu N., Doğan S., Demirok S., Gençalp İrizalp S., " X55NiCrMoV7 takım çeliğine Co-esaslı sert kaplamanın aşınma dayanımının incelenmesi', DÜMF Mühendislik Dergisi, 9:1, 205-213, 2018.

[4]. B.Chicco, W.E. Borbidge, E. Summerville., "' Experimental study of vanadium carbide and carbonitride coatings", Materials Science and Engineerin, A266, 62-67, 1999.

[5]. J.C.A. Batista., M.C.Joseph., C.Godoy,. A.Matthews., "' Micro-abrasion wear testing of PVD TiN coatings on untreated and plasma nitrided AISI H13 steel.’, Wear, 249, 971-979, 2002.

[6]. L.H. Chiu., C.F. Yang, W.C. Hsieh, A.S. Cheng., ''Effect of contact pressure on wear resistance of AISI H13 tool steels with chromium nitride and hard chromium coatings", Surface and Coatings Technology 154, 282$288,2002$. 